The Effects of grazing and watering on ecosystem $\mathrm{CO}_{2}$ fluxes vary by community phenology

Juanjuan $\mathrm{Han}^{1,2}$, Linghao $\mathrm{Li}^{2}$, Housen $\mathrm{Chu}^{4}$, Yuan Miao ${ }^{5}$, Shiping $\mathrm{Chen}^{2}$, Jiquan $\mathrm{Chen}^{3 *}$

${ }^{1 .}$ International Center for Ecology, Meteorology, and Environment, Nanjing University of Information Science and Technology, Nanjing 210044, China

${ }^{2 .}$ Key Laboratory of Vegetation and Environmental Change, Institute of Botany, Chinese Academy of Sciences, Beijing 100093, China

3. CGCEO/Geography, Michigan State University, East Lansing, Michigan 48824, USA

4. Department of Environmental Science, Policy, and Management, University of California, Berkeley, California 94720, USA

5. China and State Key Laboratory of Cotton Biology, Key Laboratory of Plant Stress Biology, College of Life Sciences, Henan University, Kaifeng, Henan 475004, China

Corresponding author:

Dr. Jiquan Chen

Email: jqchen@msu.edu

Tel: +01 5178841884

Original article 


\begin{abstract}
Grazing profoundly influences vegetation and the subsequent carbon fluxes in various ecosystems. However, little effort has been made to explore the underlying mechanisms for phenological changes and their consequences on carbon fluxes at ecosystem level, especially under the coupled influences of human disturbances and climate change. Here, a manipulative experiment (2012-2013) was conducted to examine both the independent and interactive effects of grazing and watering on carbon fluxes across phenological phases in a desert steppe. Grazing advanced or delayed phenological timing, leading to a shortened green-up phase (GrP: 23.60 days) in 2013 and browning phase (BrP: 12.48 days) in 2012 from high grazing, and insignificant effects on the reproductive phase $(\mathrm{ReP})$ in either year. High grazing significantly enhance carbon uptake, while light grazing reduce carbon uptake in ReP. Watering only delayed the browning time by 5.01 days in 2013, producing no significant effects on any phenophase. Watering promoted the net ecosystem exchange (NEE), ecosystem respiration (ER), and gross ecosystem productivity (GEP) only in the GrP. When calculating the yearly differences in phenophases and the corresponding carbon fluxes, we found that an extended GrP greatly enhanced NEE, but a prolonged ReP distinctly reduced it. The extended GrP also significantly promote GEP. Increases in growing season length appeared promoting ER, regardless of any phenophase. Additionally, the shifts in NEE appeared dependent of the variations in leaf area index (LAI).
\end{abstract}

Keyword: human disturbances; phenology; carbon; desert steppe; grazing; water 


\section{Funding sources}

This study was funded by the Natural Science Foundation of China (31229001), the "Dynamics of Coupled Natural and Human Systems (CNH)" Program of the NSF (\#1313761), the LCLUC program of NASA (NNX14AD85G), and the China Postdoctoral Science Foundation. 


\section{Introduction}

Human activities as disturbance events are increasingly reported as important drivers for ecosystem composition, structure, and function across the Earth's surface. In addition to their direct alterations of land cover type and vegetation/soil properties (de Vries et al., 2012; Liu et al., 2013; Matthews et al., 2004), indirect influences on microclimate, plant phenology, ecosystem processes (e.g, carbon uptake and emission, evapotranspiration, nutrient cycling), and functions (e.g., productivity, ecosystem diversity) are also widely recognized (Min et al., 2011; Petraglia et al., 2014; Root et al., 2005; Syvitski et al., 2005). Among many key lessons on disturbance-ecosystem relationships, the long-lasting effects (Cuddington, 2011) and interactive effects with other drivers (e.g., climate change) are still not well understood. For example, the effects of a disturbance on ecosystem processes may depend on phenology (DeForest et al., 2006; Migliavacca et al., 2015; Richardson et al., 2012), and these effects may also be coupled by the changes in climate and other natural disturbances. With an interest in plant phenology and ecosystem processes, we conducted a literature search with different sets of keywords via the Web of Science, revealing that human disturbance research (e.g., nutrient addition, land use change, grazing and heat island) had become growing concern in phenology (Fig. 1).

In the semiarid and arid regions of the Eurasian continent, grazing and water stress are among the most important drivers on ecosystem functions and dynamics (Chen et al., 2014; Hao et al., 2014; Pennington and Collins, 2007; Shao et al., 2013). For plant phenology, water is a critical agent in advancing the green-up timing (Shen et al., 2011), flowering (Crimmins et al., 2011; Prieto et al., 2008), and senescence (Han et al., 2015). However, water is not the sole limiting factor for phenological changes during the growing season (Ji and Peters, 2003); temperature and other climatic conditions can produce independent or interactive effects on phenological changes as well (Llorens and Penuelas, 2005). More importantly, grazing - the most dominant land-use practice in Eurasian pastoral lands - exerts substantial and extensive influences on phenology. It directly alters vegetation and soil properties that modify the microclimate (Yates et al., 2000). It also influences phenology indirectly due to altered biogeochemistry processes (Bremer et al., 2001), species composition and richness (Socher et al., 2013), forage quality (Rossignol et al., 2011), and interspecific competition (Medina-Roldan et al., 2012). Using green-up timing as an example, grazing via defoliation in the early growing season will yield a reduced litter layer, which is partially responsible for the increase in energy absorbed by the soil during the daytime (i.e., soil temperatures elevating in daytime; Van der Wal et al., 2001; Shao et al., 2014), and will thereby advance the green-up time. Similarly, a reduced litter layer would elevate water loss through soil evaporation (Miao et al., 2009), and possibly delaying the green-up time. While it is clear that these biotic and abiotic changes can directly or indirectly influence ecosystem processes such as carbon fluxes, phenology appears to be an integrative indicator in understanding the casual relationships between drivers and ecosystem processes. Here, we placed our focus on the variation of these biophysical regulations in different phenophases 
through a manipulative experiment of grazing and watering.

Scientific investigations on the roles of plant phenology in ecosystem functions, especially on productivity or carbon fluxes, have received increasing attention in recent years. For example, the length of a $\mathrm{CO}_{2}$ uptake period or of a growing season (GSL) is suggested to have significant direct effects on vegetation dynamics, carbon gains and losses (Chen et al. 2014; Oberbauer et al., 1998; Piao et al., 2007;

Richardson et al., 2009; Xia et al., 2015), and evapotranspiration (Liu et al., 2014). Both ground-based experimental and modeling approaches have been extensively used in these studies. Field observations tend to focus on in situ phenological timing or on reproductive successes at species level (Fitter and Fitter, 2002), while remote sensing modeling is more advantageous by delineating the beginning/ending of a growing season by tracking vegetation quantities (e.g., NDVI) at broader spatial scales (Fisher and Mustard, 2007). In comparison, little effort has been placed on understanding the mechanisms through controlled experiments at community level. This limits our understanding of the role of phenology in regulating the magnitude and dynamics of ecosystem processes such as $\mathrm{CO}_{2}$ fluxes (Migliavacca et al., 2015).

In this study, we propose a "co-flowering ratio" method to connect phenology observations and ecosystem carbon fluxes by scaling the phenology from species to community level. These phenological measures then were related to the ecosystem carbon fluxes of a manipulative experiment. This method was not designed to better integrate phenological traits from species to community, rather it is designed as a simple approach for quantifying "community phenology" from species records, in hope that it can be widely applied in phenology-carbon fluxes research.

A two-year manipulative experiment in a Eurasian steppe was conducted to examine the independent and interactive effects of grazing and watering on $\mathrm{CO}_{2}$ fluxes by phenophases. We address two fundamental questions: (i) How do grazing and watering affect phenological timing and duration both independently and interactively? (ii) Do the grazing- and watering-induced phenological shifts yield corresponding changes in $\mathrm{CO}_{2}$ fluxes?

\section{Materials and Methods}

Study area and the experiment

Our experiment was conducted in a desert steppe in Inner Mongolia ( $41^{\circ} 47^{\prime} \mathrm{N}$, $111^{\circ} 53^{\prime} \mathrm{E}, 1450 \mathrm{~m}$ a.s.1.) during 2012-2013. This region has a temperate continental climate, with a mean temperature of $14.37{ }^{\circ} \mathrm{C}$ and $16.38{ }^{\circ} \mathrm{C}$ in the growing season of 2012 and 2013, respectively. The average annual precipitation was $230 \mathrm{~mm}$ in the past 10 years, while it was $360 \mathrm{~mm}$ and $236 \mathrm{~mm}$ in 2012 and 2013, respectively. In our reference plot, there were similar, lower, higher, and almost similar soil volumetric water (VWC) in $2012(7.1 \%, 10.8 \%, 17.9 \%, 9.4 \%)$ than those in $2013(7.9 \%, 13.2 \%$, $14.5 \%, 9.7 \%$ ) at a depth of $10 \mathrm{~cm}$ before the growing season, in greening up, reproductive, and browning phase, respectively.

A randomized block experiment with three grazing levels (CK, zero; LG, 0.93 sheep half year ${ }^{-1} \mathrm{ha}^{-1}$; and HG, 2.71 sheep half year ${ }^{-1} \mathrm{ha}^{-1}$,), with three replications for each treatment, was installed since 2003 (Han et al., 2014). Base on this experiment, a 
nested design was applied with watering treatment embedded in this grazing platform (i.e., 12 blocks) in order to test the effects of grazing and watering treatment on $\mathrm{CO}_{2}$ fluxes within different phenological phases during 2012-2013. Thus, prior to the growing season of 2012, we enclosed each block within an area of $9 \times 9 \mathrm{~m}$ to avoid grazing. In each enclosure, four $1 \times 1 \mathrm{~m}$ plots were randomly installed for fluxes measurements, four $1 \times 2 \mathrm{~m}$ plots for phenological observations, ten $1 \times 1 \mathrm{~m}$ plots for community characteristic measurements, including species height, cover, biomass, and leaf area index (LAI). Each block has an area of 4 ha. Half of the total sampling plots in each treatment were randomly partitioned to the watering treatments. A hand sprinkler was used to water amounts of $5 \mathrm{~mm}$ on a biweekly basis from March to August and amounts of $10 \mathrm{~mm}$ on a weekly basis from September to early October in both years, resulting in about $30 \%$ more precipitation than that of the 10 -year average.

\section{Vegetation sampling}

Species cover, biomass, and LAI were collected monthly for each sampling plot. Aboveground vegetation was harvested by species in four quadrats $(0.5 \times 0.5 \mathrm{~m})$ from each enclosure for the aboveground biomass (AGB) and green leaf area index (LAI). A frame with 100 grids was used for estimating the total cover of the dominant species.

Five individuals of each species, when available, in each phenology-monitoring plot were tagged using insulation tape. Nine perennial forbs, three grasses, one annual forb and four shrubs were found in our experiment. The phenological observations were conducted every four to seven days. All the phenological stages were recorded from green-up to browning time along the Julian day (JD, ranging from 1 to 365 for a year) in each year by scores. The scoring method was modified from Dunne et al. (2003). For forbs, we took "0" as sprout-out leaf, "1" as unopened buds, "2" as opened flowers, " 3 " as old flowers, " 4 " as initiated fruits, " 5 " as enlarged fruits, "6" as dehisced fruits, and "7" as withered plants. For grasses, "0" as sprout-out leaf, " 0.5 " as plant booting stage, " 1 " as the presence of spikelets, " 2 " as exerted anthers or styles, "4" as past the presence of anther and styles, " 6 " as disarticulated florets, and " 7 " as withered plants. Our field recording ended when all individuals reached stages of "7". On each observation day, phenological scores of each individual were calculated by the unweight mean. For example, a plant with one bud (" 1 "), three enlarged fruits ("5"), and four senescence fruits ("7"), received a phenological score of 4.3.

Community phenology was determined by averaging the phenology of selected-species (i.e., based on the co-flowering method). We recorded the JD on "0" as the community green-up time, "1" as the budding time or the beginning of the reproduction phase, " 6 " as the fruits disarticulating or the ending of the reproduction phase, and " 7 " as the community browning time or the ending of browning phase. The length of the growing season (i.e., number of JD) was categorized into three phenophases: green-up phase (GrP: JD on " $0-1$ "), reproductive phase (ReP: JD on "16 "), and browning phase (BrP: JD on "6 - 7"). 
$\mathrm{CO}_{2}$ fluxes measurements

The net exchange of $\mathrm{CO}_{2}$ between the vegetation and the atmosphere were measured using an infrared gas exchange analyzer (IRGA; LI-840, LI-COR, Inc., Lincoln, NE, USA), attached to a static transparent chamber $(0.5 \times 0.5 \times 0.5 \mathrm{~m})$. Stainless steel square frames $(0.5 \times 0.5 \mathrm{~m})$ were installed in each plot for supporting the chamber during the measurements (Chen et al., 2009). The transparent chamber was mounted on the frames for $\sim 80$ seconds for calculating the net ecosystem exchange (NEE). After the chamber was lifted and vented, they were mounted on the frames again with a lightproof cloth for calculating ecosystem respiration (ER). Our field measurements were conducted three to four times per month. Soil temperature (Ts) was simultaneously measured using a thermocouple at the depth of $10 \mathrm{~cm}$ adjacent to the frame. Soil volumetric water content (VWC) was also simultaneously measured, by using a TDR-300 soil moisture probe (Spectrum Technologies Inc., Plainfield, IL, USA) at a depth of 0-12 cm adjacent to the frame.

Statistical analysis

Carbon fluxes calculation

The carbon fluxes were calculated as (Jasoni et al., 2005):

$$
\mathrm{F}_{\mathrm{c}}=\frac{\mathrm{VP}_{\mathrm{av}}\left(1000-\mathrm{W}_{\mathrm{av}}\right)}{\mathrm{RS}\left(\mathrm{T}_{\mathrm{av}}+273\right)} \times \frac{\mathrm{dC}^{I}}{\mathrm{dt}}
$$

where $\mathrm{F}_{\mathrm{c}}$ is the $\mathrm{CO}_{2}$ flux $\left(\mu \mathrm{mol} \mathrm{m} \mathrm{m}^{-2} \mathrm{~s}^{-1}\right), \mathrm{V}$ is the volume of dome $\left(\mathrm{m}^{3}\right), \mathrm{P}_{\mathrm{av}}$ is the average vapor pressure $(\mathrm{kPa})$ during the measurement period, $\mathrm{W}_{\mathrm{av}}$ is the average water mole fraction $\left(\mathrm{mmol} \mathrm{mol}^{-1}\right), \mathrm{R}$ is the ideal gas constant $\left(8.34 \mathrm{Jmol}^{-1} \mathrm{k}^{-1}\right), \mathrm{S}$ is the surface area covered by the chamber $\left(\mathrm{m}^{2}\right), \mathrm{T}_{\mathrm{av}}$ is the average temperature $\left({ }^{\circ} \mathrm{C}\right)$, and $\mathrm{dC} / \mathrm{dt}$ is the slope of the linear regression of $\mathrm{C}$ over time.

$$
\mathrm{NEE}=\mathrm{ER}-\mathrm{GEP}
$$

where GEP is gross ecosystem production, NEP is net ecosystem productivity, and ER is ecosystem respiration.

\section{Community phenology}

We predicted JD on phenological scores for each species through calculating these parameters. All individuals $(\mathrm{n} \leq 5)$ of the same species in each plot were averaged to calculate the mean JD by species and by plot. A polynomial regression model (Eq. 3) was applied for the predictions on green-up and browning timing.

$$
\mathrm{PHS}=a+b \times \mathrm{JD}+c \times \mathrm{JD}^{2}
$$

The growth equation of sigmoid Richard (Eq. 4,Yin et al., 2003) was applied to calculate the timing of JD for budding and fruit abscission (Han et al., 2015).

$$
\text { PHS }=a \times\left[1+(b-1) \times \mathrm{e}^{-c(\mathrm{JD}-d)}\right]^{1 /(1-b)}
$$

where PHS is the phenological scores, ranging from " 0 " to " 1 " and " 6 " to " 7 " in Eq. 3, and from " 1 " to " 6 " in Eq. 4; $a, b, c$ and $d$ are empirical coefficients estimated for each plant.

We then screened all the species and retained the dominant species for each plot. We sorted all species for its summed dominant rate (SDR) by retaining the dominate 
species when its SDR was $>0.1$. The SDR was calculated by averaging the relative biological index for each species as:

$$
\mathrm{SDR}_{i}=\frac{\sum_{1}^{n}\left(\mathrm{R}_{i} / \mathrm{R}_{\max }\right)}{\mathrm{n}}
$$

where $\mathrm{R}_{\mathrm{i}}$ is the cover $(\%)$, height $(\mathrm{cm})$, or biomass $\left(\mathrm{g} \mathrm{m}^{-2}\right)$ of the species $i$ in a plot, $R_{\max }$ is the corresponding maximum value of $\mathrm{R}_{\mathrm{i}}$ in the plots, and $n$ is the number of variables $(\mathrm{n}=3)$.

We integrated the phenology of the dominant species to the community. Because only a certain number of dominate species flowering within a period could represent the community phenology, we screened the dominate species by confirming its all co-flowering species to assure the dominant species has $>30 \%$ of the its total richness. The co-flowering method is defined as:

$$
\mathrm{JD}_{\mathrm{PHS}}=\frac{\sum_{1}^{n} J D_{i}}{n} \quad \mathrm{X} i \geqslant(\text { Richness } \times \text { rate })
$$

where $\mathrm{JD}_{\mathrm{PHS}}$ is the community phenological timing for green-up timing, budding timing, fruits disarticulating timing, and browning timing, $i$ is species, $\mathrm{X} i$ is the number of co-flowering species for a focal species, Richness is the total number of the species in a community, rate is a co-flowering ratio in a community set to $30 \%$ in this study, $\mathrm{n}$ is the total number of the species for a community, and $\mathrm{JD}_{i}$ is the phenological timing of a focal species. Following these rules, we removed six dominant species out of the community phenology (Fig. 2): Stipa breviflora, Allium anisopodium, Tripolium vulgare, Stipa krylovii, Potentilla bifurca, and Astragalus linn. Therefore, these timings, which constituted the community phenological durations, were labeled as GrP, ReP, and BrP.

\section{Data analysis}

We performed the linear mixed-effects model analysis (function "lme", "nlme" package in $\mathrm{R}$ ) to test the random effects of watering nested in grazing (block) and the fixed effects of year (Y), grazing $(G)$, watering (W) for averaged cover, AGB and LAI for each community phenophase. A linear mixed-effects model analysis was also conducted to verify the same random and fixed effects for the vegetative timing of green-up $\left(\mathrm{Phe}_{0}\right)$, browning timing ( $\mathrm{Phe}_{7}$ :), budding $\left(\mathrm{Phe}_{1}\right)$, fruits disarticulating timing (Phe 6 :), and the durations of GrP, ReP, and $\mathrm{BrP}$, and $\mathrm{CO}_{2}$ fluxes (NEE, ER, GEP) within each phase. Our initial analysis indicted that there was no significant interactive effects from grazing and watering on any variable. Consequently, we used the glht (i.e., "multcomp" package in R) as the post-hoc tests following an lme analysis. Regression analysis was used to quantify the relationship between the interannual-changed phenophases and the corresponding $\mathrm{CO}_{2}$ fluxes as well as the relationship between interannual changes in functional traits ( $\triangle \mathrm{LAI}, \triangle \mathrm{AGB}, \Delta$ cover) and $\mathrm{CO}_{2}$ fluxes within each phenophase. All statistical analyses were conducted using the $R$ version 3.0.2 RC (www.r-project.org). 


\section{Results}

There were significantly year-differences on all community characteristics among the three phenophases (Table 1). In GrP, inter-annual variations had no significant effect on AGB and cover between 2012 and 2013; but they significantly increased LAI in $2013(P<0.001)$. In ReP and BrP, there appeared an elevated AGB, cover and LAI in 2012 than those in 2013.

Grazing and watering produced differential effects on each community functional traits in vegetation phases (Table 1). In GrP, grazing significant reduced the AGB by 28.42\% in LG of 2012 and AGB by 39.72\% and 33.73\% in HG of 2012 and 2013 ( $P$ $<0.001)$, respectively. Grazing decreased the cover by $40.15 \%$ in LG of 2012 and by $24.09 \%$ and $29.22 \%$ in HG of 2012 and 2013 ( $P<0.001$ ), respectively. Additionally, grazing reduced LAI by $30.35 \%$ and $21.30 \%$ in LG of 2012 and 2013, respectively; and by $34.40 \%$ and $38.84 \%$ in $\mathrm{HG}$ of 2012 and $2013(P<0.001)$, respectively. Watering significantly promoted the AGB (2012: $36.61 \%, P=0.001)$, LAI (2012: 64.59\%, $P<0.001 ; 2013: 20.71 \%, P=0.002)$, and cover (2012: $23.04 \%, P=0.002)$. In BrP, grazing marginally reduced the LAI $(48.44 \%)$ in HG than LG $(P=0.052)$, however, there were no significant effects on AGB and cover. Watering produced no significant effects on AGB, LAI, and cover.

For reproductive phase, grazing reduced the AGB by $35.42 \%$ and $35.19 \%$ in LG and HG of $2012(P<0.001)$, respectively. Grazing reduced the cover by $26.06 \%$ in both LG and HG of $2012(P<0.001)$; and reduced the LAI by $10.31 \%$ in LG of 2012 $(P=0.05)$. Watering distinctly promoted the AGB $(2012: 27.84 \%, P=0.04)$, LAI (2013: 33.74\%, $P=0.023$ ), and cover (2012: 30.32\%, $P=0.001)$.

Grazing produced complex effects on community phenological timing, while watering only delayed the browning time in 2013 (Table 2). Grazing delayed the onset of green-up in both years, with 8.5 days in 2012 and 18.33 days in 2013 from HG ( $P$ $<0.001)$. However, grazing had contradicting influences on budding time between 2012 and 2013, with significant delay of 14.07 days in HG and 8.31 days in LG in 2012, while advanced the time by 5.26 days in HG in $2013(P=0.006)$. Grazing only delayed the onset of fruits disarticulating in 2012 by 9.38 days in $\mathrm{HG}(P=0.007)$. Additionally, differential grazing levels yielded opposite influences on browning time, advancing it by 2.63 days in HG while delaying it 3.08 days in LG in 2012-2013 ( $P=$ $0.002)$. Watering only delayed the browning time by 5.01 days $(P=0.003)$ in 2013 , but no significant differences were found for other timings.

Grazing shortened some community phenological phases, while watering produced no effects on these phenophases (Table 2). Grazing significantly compressed GrP by 23.60 days in HG of 2013 and BrP by 12.48 days in $\mathrm{HG}(P<0.001)$ of 2012, but had no effects on $\operatorname{ReP}(P=0.641)$. No significant influences among phenological phases were found due to watering.

Grazing and watering affected the carbon fluxes in different magnitudes and directions within a phenological phase (Table 1 Fig.3). In GrP, grazing significantly decreased the NEE by $37.85 \%$ in HG and $21.78 \%$ in LG of 2013, but not in $2012(P<$ $0.001)$. Grazing significantly decreased the GEP by $28.28 \%$ in HG of $2013(P<0.01)$. There were no effects from grazing on ER in both years. Watering significantly 
promoted the NEE by $57.22 \%(P<0.001)$ in 2012 , ER by $22.14 \%(P=0.013)$ in 2012 and $31.08 \%(P<0.001)$ in 2013 , and elevated GEP by $37.15 \%(P<0.01)$ and $25.22 \%(P=0.002)$ in the two years, respectively. In ReP, grazing produced opposite consequences on NEE between LG and HG; it enhanced NEE by $8.14 \%$ in HG and reduced it by $12.17 \%$ in LG of $2012(P<0.001)$. Grazing decreased the ER by $25.07 \%$ in LG and by $18.29 \%$ in HG of $2012(P<0.001)$ and also reduced the GEP in LG by $13.77 \%$ during $2012(P<0.001)$. Watering produced no differences on NEE, ER, and GEP. In BrP, grazing only reduced the ER by $29.33 \%(P=0.020)$. There were no significant differences on NEE, ER, and GEP from watering.

High correlations between phenophases and carbon fluxes were found, but with opposite directions among NEE, ER and GEP. Inter-annual extended phenological days significantly enhanced the NEE in $\operatorname{GrP}\left(P<0.001 ; \mathrm{R}^{2}=0.41\right)$, while notably reducing the NEE in $\operatorname{ReP}\left(P=0.001 ; \mathrm{R}^{2}=0.25\right.$, Fig. $\left.4 \mathrm{a}, \mathrm{b}\right)$. The extended days largely enhanced the ER in all phenophases (GrP: $P=0.008, \mathrm{R}^{2}=0.18$; ReP: $P<0.001, \mathrm{R}^{2}=$ 0.30; BrP: $P=0.01, \mathrm{R}^{2}=0.17$, Fig. $\left.4 \mathrm{~d}, \mathrm{e}, \mathrm{f}\right)$. The extended days significantly enhanced the GEP $\left(P<0.01, \mathrm{R}^{2}=0.42\right.$, Fig. $\left.4 \mathrm{~g}\right)$ in GrP. Additionally, the annual-induced changes of NEE showed positive linear correlations with the changes of LAI with different slopes and R square in the $\operatorname{GrP}\left(P=0.007 ; \mathrm{R}^{2}=0.37\right)$ and $\mathrm{ReP}$ $\left(P=0.06 ; \mathrm{R}^{2}=0.16\right)$, respectively (Table 2 , Fig. 5a, b).

\section{Discussion}

Phenological timing

Grazing-induced changes in flora demography, functions, and microclimate seemed reflected by phenological timing. Grazing delayed community green-up timing by an average of 13.42 days during the two-year study period, with more delays in community level than that at species level (5.67 days) (Han et al., 2015). These delays are probably because, through the reduction of litter layer, the heat flux into the soil that increased the differences between at day and night (Shao et al., 2014), resulting in lowered cumulative temperature, and then delaying the timing of leaf out. Poveda et al. (2003) reported that leaf herbivores shortened the flowering duration and reduced reproductive productivity in mustard plants, which will result in fruits' disarticulating time to be advanced. However, this is in contradictory with our results, where we found that grazing delayed the disarticulating time of fruits. The delays in fruiting timing were mainly resulted from the coupled changes between plant community and grazing animals. For example, to decrease ecosystem instability to grazing, the grazed community may enhance pollination chances and increase flora abundance (i.e., delaying the disarticulating time) to maintain the ecosystem balance (Diaz et al., 2007; Potts et al., 2003; Taylor et al., 2002; Tessema et al., 2011). For browning time, inverse grazing effects were found between LG and HG, where high grazing advanced the timing and light grazing delayed it over the study period. These may be attributed to the lowered forage quality and quantity in HG than LG; specifically, intensive trampling would reduce foliar water content and nutrients more than light grazing would (Tessema et al., 2011). Additonally, low LAI in HG also means reduced total photosynthesis, which will further accelerate yellowing (Fig. 6). 
Interestingly, we found that watering had insignificant effects on phenology, except for evidently delays in browning time in 2013 (Table 1). However, previous studies did find that watering affected the green-up timing (Pennington and Collins, 2007; Penuelas et al., 2004) and summer flowering (Crimmins et al., 2011). Clearly, we cannot reach a conclusion on the role of watering in altering plant phenology based on the existing evidences, suggesting the needs for continuing similar studies at different ecosystems.

\section{$\mathrm{CO}_{2}$ fluxes within phenophases}

Differentiated changes in the magnitudes of GEP and ER seemed to be responsible for the significant increases in NEE from high grazing and decreases from light grazing in reproductive phase of 2012(Table 1, Fig. 3). During this period, lowered LAI in LG than that in the reference plots resulted in a significantly lower carbon uptake (i.e., NEE) (Table 1). High grazing enhanced the carbon uptake, probably through damaging the plant reproductive success (i.e., promoting vegetative growth) and, consequently, promoted photosynthesis. These findings further reinforced our previous finding - grazing enhanced carbon uptake in middle of growing season (i.e., around reproductive phase) - that only high grazing promoted the carbon uptake (Han et al., 2014). As for watering, we found that it only affected the NEE, ER, and GEP in the green-up phases (Table 1). This surprising finding on the role of water addition in this dry system needs further investigations.

\section{Carbon fluxes by phenophases}

Phenological contributions to the carbon fluxes are not simply linear with GSL, which is commonly practiced in some ecosystems models (Xia et al., 2015). Using NEE as an example, GrP and BrP accounted for the majority of days (116, 34 days) in GSL (190 days), with an average NEE of $-3.298,-2.198 \mu \mathrm{mol} \mathrm{m}^{-2} \mathrm{~s}^{-1}$, respectively, while ReP lasted only 40 days with an average NEE of $-8.378 \mu \mathrm{mol} \mathrm{m}^{-2} \mathrm{~s}^{-1}$. Thus, vegetation and reproductive phenology may have different relationships with the corresponding NEE.

Furthermore, the extended phenological durations would not warrant an increased carbon uptake at the community level. When calculating the yearly differences on phenophases and the corresponding carbon fluxes, the increased green-up duration significantly enhanced the carbon sink in GrP, while the extended reproductive duration in ReP decreased it (Fig. 4a, b). This may be because of the relative contributions of vegetative and reproductive tissues to both photosynthesis and respiration. Specifically, the prolonged duration of the green-up phase would facilitate the additional green leaves, leading to a higher photosynthesis than respiration, while the extended phenological duration in the reproductive phase will synthetize more flowers and fruits that contribute mostly to the respiration. We also found that LAI was an important factor partially determining the phenological contributions on carbon exchange, which accounted for the NEE variations by $37 \%$ and $16 \%$ in GrP and ReP, respectively (Fig. 5).

The extended growing season's contributions on ecosystem photosynthesis and 
respiration were depends on their physiological and biochemical processes. Compared to NEE, expanded photoperiod in any time of the growing season would enhance the ecosystem respiration (i.e., ER), revealing the ecosystem respiration as a biochemical process and accompanying with synthetizing energy (Fig, 4d, e, f). The increased duration only in green-up phase could promote ecosystem photosynthesis (i.e., GEP) significantly (Fig. 4g), indicating that there may have high content of chlorophyll in this phase for converting the light to electric energy, promoting photosynthesis than that in other phases. Richardson et al. (2009) reported that the earlier onset of spring does not always bring a higher seasonal or annual GPP and ER, but that it significantly enhances springtime NEP by $2-4 \mathrm{~g} \mathrm{C} \mathrm{m}^{-2} \mathrm{~d}^{-1}$. However, their study primarily highlighted the relationships only on spring phenology, ignoring the intrinsic relations on reproductive or browning phenology; whereas we provided a comprehensive evaluation on the phenological regulations on carbon cycling.

\section{Conclusions}

Grazing as the primary land-use practice in semiarid ecosystems changed the green-up and browning phases and produced differentiating effects on carbon fluxes. Watering, as the most critical climatic driver, had positive effects on browning time and increased carbon fluxes only in green-up phase. The prolonged growing season length does not warrant a high productivity as we found that only extended green-up phases promoted carbon uptake. Leaf area index was an important factor regulating these consequences. Clearly, future research on the role of phenological changes on carbon fluxes should include the phenophase in understanding and modeling ecosystem processes.

\section{Acknowledgements}

We thank Guodong Han for maintaining the grazing platform and constructive suggestions for phenological observation. We also thank to Gabriela Shirkey for language editing of the manuscript. Our research were supported by the Natural Science Foundation of China (31229001), the "Dynamics of Coupled Natural and Human Systems (CNH)" Program of the NSF (\#1313761), and China Postdoctoral Science Foundation.

\section{Reference}

Bremer, D. J., Auen, L. M., Ham, J. M., Owensby, C. E., 2001. Evapotranspiration in a prairie ecosystem: Effects of grazing by cattle. Agron. J. 93, 338-348.

Chen, J., Wan, S., Henebry, G., Qi, J., Gutman, G., Sun, G., Kappas, M., 2014. Dryland East Asia: land dynamics amid social and climate change. Walter de Gruyter, pp23-38.

Chen, S., Lin, G., Huang, J., Jenertte, G. D., 2009. Dependence of carbon sequestration on the differential responses of ecosystem photosynthesis and respiration to rain pulses in a semiarid steppe. Glob. Change Biol. 15, 2450-2461.

Crimmins, T. M., Crimmins, M. A., Bertelsen, C. D., 2011. Onset of summer flowering in a 'Sky Island'is driven by monsoon moisture. New Phytol. 191, 
468-479.

Chen, T., et al., 2014. Global cropland monthly gross primary production in the year 2000. Biogeosciences. 11, 3871-3880.

Cuddington, K., 2011. Legacy effects: The persistent impact of ecological interactions. Biol. Theory. 6, 203-210.

de Vries, F. T., Liiri, M. E., Bjornlund, L., Setala, H. M., Christensen, S., Bardgett, R. D., 2012. Legacy effects of drought on plant growth and the soil food web. Oecologia. 170, 821-833.

DeForest, J. L., Noormets, A., McNulty, S. G., Sun, G., Tenney, G., Chen, J., 2006. Phenophases alter the soil respiration - temperature relationship in an oak-dominated forest. Int. J. Biometeorol. 51, 135-144.

Diaz, S., Lavorel, S., McIntyre, S., Falczuk, V., Casanoves, F., Milchunas, D. G., Skarpe, C., Rusch, G., Sternberg, M., Noy-Meir, I., Landsberg, J., Zhang, W., Clark, H., Campbell, B. D., 2007. Plant trait responses to grazing - a global synthesis. Glob. Change Biol. 13, 313-341.

Dunne, J. A., Harte, J., Taylor, K. J., 2003. Subalpine meadow flowering phenology responses to climate change: integrating experimental and gradient methods. Ecol. Monogr. 73, 69-86.

Fisher, J. I., Mustard, J. F., 2007. Cross-scalar satellite phenology from ground, Landsat, and MODIS data. Remote Sens. Environ. 109, 261-273.

Fitter, A. H., Fitter, R. S. R., 2002. Rapid changes in flowering time in British plants. Science. 296, 1689-1691.

Hao, L., et al., 2014. Effects of precipitation on grassland ecosystem restoration under grazing exclusion in Inner Mongolia, China. Landscape Ecol. 1-17.

Han, J., Chen, J., Han, G., Shao, C., Sun, H., Li, L., 2014. Legacy effects from historical grazing enhanced carbon sequestration in a desert steppe. J. Arid Environ. 107, 1-9.

Han, J., Chen, J., Xia, J., Li, L., 2015. Grazing and watering alter plant phenological processes in a desert steppe community. Plant Ecol. DOI:

$10.1007 / \mathrm{s} 11258-015-0462-\mathrm{z}$

Jasoni, R. L., Smith, S. D., Arnone, J. A., 2005. Net ecosystem $\mathrm{CO}_{2}$ exchange in Mojave Desert shrublands during the eighth year of exposure to elevated $\mathrm{CO}_{2}$. Glob. Change Biol. 11, 749-756.

Ji, L., Peters, A. J., 2003. Assessing vegetation response to drought in the northern Great Plains using vegetation and drought indices. Remote Sens. Environ. 87, 85-98.

Liu, Y., Zhuang, Q., Chen, M., Pan, Z., Tchebakova, N., Sokolov, A., Kicklighter, D., Melillo, J., Sirin, A., Zhou, G., He, Y., Chen, J., Bowling, L., Miralles, D., Parfenova, E., 2013. Response of evapotranspiration and water availability to changing climate and land cover on the Mongolian Plateau during the 21st century. Global Planetary Change. 108, 85-99.

Liu, Y., Zhuang, Q., Pan, Z., Miralles, D., Tchebakova, N., Kicklighter, D., Chen, J., Sirin, A., He, Y., Zhou, G., Melillo, J., 2014. Response of evapotranspiration and water availability to the changing climate in Northern Eurasia. Climatic Change. 
126, 413-427.

Llorens, L., Penuelas, J., 2005. Experimental evidence of future drier and warmer conditions affecting flowering of two co-occurring Mediterranean shrubs. Int. J. Plant Sci. 166, 235-245.

Matthews, H. D., Weaver, A. J., Meissner, K. J., Gillett, N. P., Eby, M., 2004. Natural and anthropogenic climate change: incorporating historical land cover change, vegetation dynamics and the global carbon cycle. Clim. Dynam. 22, 461-479.

Medina-Roldan, E., Paz-Ferreiro, J., Bardgett, R. D., 2012. Grazing-induced effects on soil properties modify plant competitive interactions in semi-natural mountain grasslands. Oecologia. 170, 159-69.

Miao, H., Chen, S., Chen, J., Zhang, W., Zhang, P., Wei, L., Han, X., Lin, G., 2009. Cultivation and grazing altered evapotranspiration and dynamics in Inner Mongolia steppes. Agr. Forest Meteorol. 149, 1810-1819.

Migliavacca, M., Reichstein, M., Richardson, A. D., Mahecha, M. D., Cremonese, E., Delpierre, N., Galvagno, M., Law, B. E., Wohlfahrt, G., Black, T. A., Carvalhais, N., Ceccherini, G., Chen, J., Gobron, N., Koffi, E., Munger, J. W., Perez-Priego, O., Robustelli, M., Tomelleri, E., Cescatti, A., 2015. Influence of physiological phenology on the seasonal pattern of ecosystem respiration in deciduous forests. Glob. Change Biol. 21, 363-376.

Min, S.-K., Zhang, X., Zwiers, F. W., Hegerl, G. C., 2011. Human contribution to more-intense precipitation extremes. Nature. 470, 378-381.

Oberbauer, S. F., Starr, G., Pop, E. W., 1998. Effects of extended growing season and soil warming on carbon dioxide and methane exchange of tussock tundra in Alaska. J. Geophys. Res-Atmos. 103, 29075-29082.

Pennington, D. D., Collins, S. L., 2007. Response of an aridland ecosystem to interannual climate variability and prolonged drought. Landscape Ecol. 22, 897-910.

Penuelas, J., Filella, I., Zhang, X. Y., Llorens, L., Ogaya, R., Lloret, F., Comas, P., Estiarte, M., Terradas, J., 2004. Complex spatiotemporal phenological shifts as a response to rainfall changes. New Phytol. 161, 837-846.

Petraglia, A., Tomaselli, M., Mondoni, A., Brancaleoni, L., Carbognani, M., 2014. Effects of nitrogen and phosphorus supply on growth and flowering phenology of the snowbed forb Gnaphalium supinum L. Flora. 209, 271-278.

Piao, S., Friedlingstein, P., Ciais, P., Viovy, N., Demarty, J., 2007. Growing season extension and its impact on terrestrial carbon cycle in the Northern Hemisphere over the past 2 decades. Global Biogeochem. Cycle. 21, GB3018.

Potts, S. G., Vulliamy, B., Dafni, A., Ne'eman, G., Willmer, P., 2003. Linking bees and flowers: How do floral communities structure pollinator communities? Ecology. 84, 2628-2642.

Poveda, K., Steffan-Dewenter, I., Scheu, S., Tscharntke, T., 2003. Effects of belowand above-ground herbivores on plant growth, flower visitation and seed set. Oecologia. 135, 601-605.

Prieto, P., Peñuelas, J., Ogaya, R., Estiarte, M., 2008. Precipitation-dependent flowering of Globularia alypum and Erica multiflora in Mediterranean shrubland 
under experimental drought and warming, and its inter-annual variability. Ann. Bot. 102, 275-285.

Richardson, A. D., Anderson, R. S., Arain, M. A., Barr, A. G., Bohrer, G., Chen, G., Chen, J. M., Ciais, P., Davis, K. J., Desai, A. R., Dietze, M. C., Dragoni, D., Garrity, S. R., Gough, C. M., Grant, R., Hollinger, D. Y., Margolis, H. A., McCaughey, H., Migliavacca, M., Monson, R. K., Munger, J. W., Poulter, B., Raczka, B. M., Ricciuto, D. M., Sahoo, A. K., Schaefer, K., Tian, H., Vargas, R., Verbeeck, H., Xiao, J., Xue, Y., 2012. Terrestrial biosphere models need better representation of vegetation phenology: results from the North American Carbon Program site synthesis. Glob. Change Biol. 18, 566-584.

Richardson, A. D., Hollinger, D. Y., Dail, D. B., Lee, J. T., Munger, J. W., O'Keefe, J., 2009. Influence of spring phenology on seasonal and annual carbon balance in two contrasting New England forests. Tree Physiol. 29, 321-331.

Root, T. L., MacMynowski, D. P., Mastrandrea, M. D., Schneider, S. H., 2005. Human-modified temperatures induce species changes: Joint attribution. Proc. Nat. Acad. Sci. USA. 102, 7465-7469.

Rossignol, N., Bonis, A., Bouzille, J. B., 2011. Impact of selective grazing on plant production and quality through floristic contrasts and current-year defoliation in a wet grassland. Plant Ecol. 212, 1589-1600.

Shao, C., Chen, J., Li, L., 2013. Grazing alters the biophysical regulation of carbon fluxes in a desert steppe. Environ. Res. Lett. 8, 025012.

Shao, C., Li, L., Dong, G., Chen, J., 2014. Spatial variation of net radiation and its contribution to energy balance closure in grassland ecosystems. Ecol. Process., $3(1), 1-11$.

Shen, M., Tang, Y., Chen, J., Zhu, X., Zheng, Y., 2011. Influences of temperature and precipitation before the growing season on spring phenology in grasslands of the central and eastern Qinghai-Tibetan Plateau. Agr. Forest Meteorol. 151, 1711-1722.

Socher, S. A., Prati, D., Boch, S., Müller, J., Baumbach, H., Gockel, S., Hemp, A., Schöning, I., Wells, K., Buscot, F., Kalko, E. K. V., Linsenmair, K. E., Schulze, E.-D., Weisser, W. W., Fischer, M., 2013. Interacting effects of fertilization, mowing and grazing on plant species diversity of 1500 grasslands in Germany differ between regions. Basic Appl. Ecol. 14, 126-136.

Syvitski, J. P., Vörösmarty, C. J., Kettner, A. J., Green, P., 2005. Impact of humans on the flux of terrestrial sediment to the global coastal ocean. Science. 308, 376-380.

Taylor, R. B., Sotka, E., Hay, M. E., 2002. Tissue-specific induction of herbivore resistance: seaweed response to amphipod grazing. Oecologia. 132, 68-76.

Tessema, Z., De Boer, W., Baars, R., Prins, H., 2011. Changes in soil nutrients, vegetation structure and herbaceous biomass in response to grazing in a semi-arid savanna of Ethiopia. J. Arid Environ. 75, 662-670.

Van der Wal, R., van Lieshout, S. M., Loonen, M. J., 2001. Herbivore impact on moss depth, soil temperature and arctic plant growth. Polar Biol. 24, 29-32.

Xia, J., Niu, S., Ciais, P., Janssens, I. A., Chen, J., Ammann, C., Arain, A., Blanken, P. D., Cescatti, A., Bonal, D., Buchmann, N., Curtis, P. S., Chen, S., Dong, J., 
Flanagan, L. B., Frankenberg, C., Georgiadis, T., Gough, C. M., Hui, D., Kiely, G., Li, J., Lund, M., Magliulo, V., Marcolla, B., Merbold, L., Montagnani, L., Moors, E. J., Olesen, J. E., Piao, S., Raschi, A., Roupsard, O., Suyker, A. E., Urbaniak, M., Vaccari, F. P., Varlagin, A., Vesala, T., Wilkinson, M., Weng, E., Wohlfahrt, G., Yan, L., Luo, Y., 2015. Joint control of terrestrial gross primary productivity by plant phenology and physiology. Proc. Nat. Acad. Sci. USA. 112, 2788-2793.

Yates, C. J., Norton, D. A., Hobbs, R. J., 2000. Grazing effects on plant cover, soil and microclimate in fragmented woodlands in south - Western Australia: implications for restoration. Austral Ecol. 25, 36-47.

Yin, X. Y., Goudriaan, J., Lantinga, E. A., Vos, J., Spiertz, H. J., 2003. A flexible sigmoid function of determinate growth. Ann. Bot. 91, 361-371. 
Table 1. Changes (\%) in aboveground biomass (AGB), leaf area index (LAI), canopy cover, ecosystem net exchange (NEE), ecosystem respiration (ER), and gross ecosystem productivity (GEP) within the green-up phase (GrP), reproductive phase $(\mathrm{ReP})$, and browning phase $(\mathrm{BrP})$, respectively, which were induced by grazing and watering in 2012 and 2013.

\begin{tabular}{|c|c|c|c|c|c|c|}
\hline \multirow[b]{3}{*}{ Variables } & \multicolumn{4}{|c|}{ Grazing-induced changes } & \multirow{2}{*}{\multicolumn{2}{|c|}{$\begin{array}{c}\text { Watering-induced } \\
\text { changes }\end{array}$}} \\
\hline & \multicolumn{2}{|c|}{ Low grazing } & \multicolumn{2}{|c|}{ High grazing } & & \\
\hline & 2012 & 2013 & 2012 & 2013 & 2012 & 2013 \\
\hline $\mathrm{AGB}_{\mathrm{GrP}}$ & $-28.42^{* *}$ & -14.08 & $-39.72^{* *}$ & $-33.73^{* *}$ & $36.61^{* *}$ & 11.56 \\
\hline $\mathrm{AGB}_{\mathrm{ReP}}$ & $-35.42^{* *}$ & -20.62 & $-35.19^{* *}$ & -31.9 & $27.84^{*}$ & 13.72 \\
\hline $\mathrm{AGB}_{\mathrm{BrP}}$ & -16.63 & -0.45 & -11.91 & 23.93 & 26.02 & 17.87 \\
\hline $\mathrm{LAI}_{\mathrm{GrP}}$ & $-30.35^{*}$ & $-21.3^{* *}$ & $-34.4^{* *}$ & $-38.84^{* *}$ & $64.59^{* *}$ & $20.71^{* *}$ \\
\hline $\mathrm{LAI}_{\mathrm{ReP}}$ & $-10.31^{*}$ & -16.19 & -2.95 & -10.12 & 13.13 & $33.74^{*}$ \\
\hline $\mathrm{LAI}_{\mathrm{BrP}}$ & 28.56 & $14.08^{*}$ & -19.04 & $-35.19^{*}$ & -16.74 & 0.00 \\
\hline Cover $_{\mathrm{GrP}}$ & $-40.15^{* *}$ & -12.52 & $-24.09^{* *}$ & $-29.22^{* *}$ & $23.04^{* *}$ & 15.77 \\
\hline Cover $_{\text {ReP }}$ & $-26.06^{* *}$ & -17.61 & $-26.06^{* *}$ & -26.42 & $30.32^{* *}$ & 9.10 \\
\hline Cover $_{\mathrm{BrP}}$ & -20.43 & 32.90 & -22.28 & 52.26 & 18.89 & 3.08 \\
\hline $\mathrm{NEE}_{\mathrm{GrP}}$ & -24.53 & $-21.78^{*}$ & -15.12 & $-37.85^{* *}$ & $57.22^{* *}$ & 20.73 \\
\hline $\mathrm{NEE}_{\mathrm{ReP}}$ & $-12.17^{* *}$ & -8.24 & $8.14^{*}$ & 12.36 & -2.15 & 18.67 \\
\hline $\mathrm{NEE}_{\mathrm{BrP}}$ & 8.72 & 13.93 & 11.42 & 3.34 & -2.78 & 17.07 \\
\hline $\mathrm{ER}_{\mathrm{GrP}}$ & -13.31 & -14.51 & -7.74 & -15.83 & $22.14 *$ & $31.08 * *$ \\
\hline $\mathrm{ER}_{\mathrm{ReP}}$ & $-25.07^{* *}$ & -15 & $-18.29^{*}$ & -9.56 & 7.22 & 4.87 \\
\hline $\mathrm{ER}_{\mathrm{BrP}}$ & $-29.33^{* *}$ & -7.17 & -9.59 & -8.86 & 10.14 & 7.68 \\
\hline $\mathrm{GEP}_{\mathrm{GrP}}$ & -18.68 & -18.85 & -11.27 & $-28.28^{* *}$ & $37.15^{* *}$ & $25.22^{* *}$ \\
\hline $\mathrm{GEP}_{\mathrm{ReP}}$ & $-13.77^{*}$ & -16.1 & 0.27 & 1.2 & 0 & 7.84 \\
\hline $\mathrm{GEP}_{\mathrm{BrP}}$ & -4.35 & 3.29 & 0 & -3.03 & -2.78 & 45.45 \\
\hline
\end{tabular}

$*$ *** Indicates significant and highly significant differences from control, $P<0.05, P$ $<0.01$, respectively. There were no significant interactive effects between grazing and watering. 
Table 2. Shifted days in green-up ( $\left.\mathrm{Phe}_{0}\right)$, budding $\left(\mathrm{Phe}_{1}\right)$, fruit maturing $\left(\mathrm{Phe}_{6}\right)$, browning timing $\left(\mathrm{Phe}_{7}\right)$, green-up phase $(\mathrm{GrP})$, reproductive phase $(\mathrm{ReP})$, and browning phase $(\mathrm{BrP})$, which were induced by grazing and watering in 2012 and 2013.

\begin{tabular}{|c|c|c|c|c|c|c|}
\hline \multirow[b]{3}{*}{ Variables } & \multicolumn{4}{|c|}{ Grazing-induced changes } & \multirow{2}{*}{\multicolumn{2}{|c|}{$\begin{array}{c}\text { Watering-induced } \\
\text { changes }\end{array}$}} \\
\hline & \multicolumn{2}{|c|}{ Low grazing } & \multicolumn{2}{|c|}{ High grazing } & & \\
\hline & 2012 & 2013 & 2012 & 2013 & 2012 & 2013 \\
\hline $\mathrm{Phe}_{0}$ & 3.83 & 1.83 & $8.5^{* *}$ & $18.33^{* *}$ & -0.33 & -1.00 \\
\hline $\mathrm{Phe}_{1}$ & $8.31^{* *}$ & -1.34 & $14.07^{* *}$ & $-5.26^{*}$ & 1.24 & 2.82 \\
\hline $\mathrm{Phe}_{6}$ & 5.36 & -0.48 & $9.38^{* *}$ & 1.07 & 2.12 & -0.63 \\
\hline $\mathrm{Phe}_{7}$ & $2.10^{*}$ & $4.07 *$ & $-3.10^{*}$ & $-2.15^{*}$ & 2.66 & $5.01^{*}$ \\
\hline GrP & 4.47 & -3.20 & 5.57 & $-23.60^{* *}$ & 3.82 & 1.58 \\
\hline $\mathrm{ReP}$ & -2.94 & 0.89 & -4.69 & 6.34 & 0.87 & -3.45 \\
\hline $\mathrm{BrP}$ & -3.26 & 4.55 & $-12.48^{* *}$ & -3.22 & 0.54 & 5.64 \\
\hline
\end{tabular}




\section{Figures Legends}

Fig. 1 Summary of publications (1996-2014) on the effects of human disturbances on plant phenology. The literature search was conducted by using the following keywords in "Web of Science (ISI)". Total: Title = "phenolog*" OR "length of growing season" OR "flowering date" in Ecology related fields. Each human disturbance, such as "grazing" was run as Title $=$ (phenolog* OR length of growing season OR flowering date) and And Topic = (grazing), respectively. The underlined values are the number of publications. The left and right axes show the number of publication by year and in total, respectively.

Fig. 2 The accumulative frequency of flowering individuals over time (DOY) in 2012 (a) and 2013 (b). We assumed that the number of co-flowering species were $>30 \%$ of total species richness.

Fig. 3 Grazing effects on $\mathrm{CO}_{2}$ fluxes (NEE, ER, GEP) by phenophases. GrP: green-up phase; ReP: reproductive phase; BrP: browning phase. * Indicates $P<0.05$; **Indicates $P<0.01$.

Fig. 4 The linear correlation between annually changed $\mathrm{CO}_{2}$ fluxes (NEE, ER, GEP) and the changes of length during green-up phase ( $\mathrm{GrP}, \mathrm{a}, \mathrm{d}, \mathrm{g})$, reproductive phase (ReP, b, e, h), and browning phase (BrP, c, f, i), respectively (reps = 36). (a): $P<$ 0.001 , slope $=-0.066, \mathrm{R}^{2}=0.41 ;(\mathrm{b}): P=0.001$, slope $=0.054, \mathrm{R}^{2}=0.25 ;(\mathrm{d}): P=$ 0.008 , slope $=0.023, \mathrm{R}^{2}=0.18$; (e): $P<0.001$, slope $=0.044, \mathrm{R}^{2}=0.30$; (f): $P=0.01$, slope $=0.018, \mathrm{R}^{2}=0.17 ;(\mathrm{g}): P<0.01$, slope $=0.089, \mathrm{R}^{2}=0.42$.

Fig. 5 The linear correlation between annual changes in NEE and LAI in green-up phase $(\mathrm{GrP}, \mathrm{a})$ and reproductive phase $(\mathrm{ReP}, \mathrm{b})($ reps $=18)$. There were significant annual differences between NEE and LAI in $\operatorname{GrP}(P<0.001)$ and $\operatorname{ReP}(P<0.001)$, but not in $\operatorname{BrP}(P=0.108)$. We only present the relationships for $\mathrm{GrP}$ and $\operatorname{ReP}$.

Fig. 6 Annual mean and standard deviation of the community LAI under six treatments $($ reps $=6)$ in browning phase $(\mathrm{BrP})$. CK_0: no grazing; LG_0: light grazing; HG_0: high grazing; CK_1: no grazing plus watering; LG_1: light grazing plus watering; $\mathrm{HG}_{-} 1$ : high grazing plus watering. 
Fig. 1

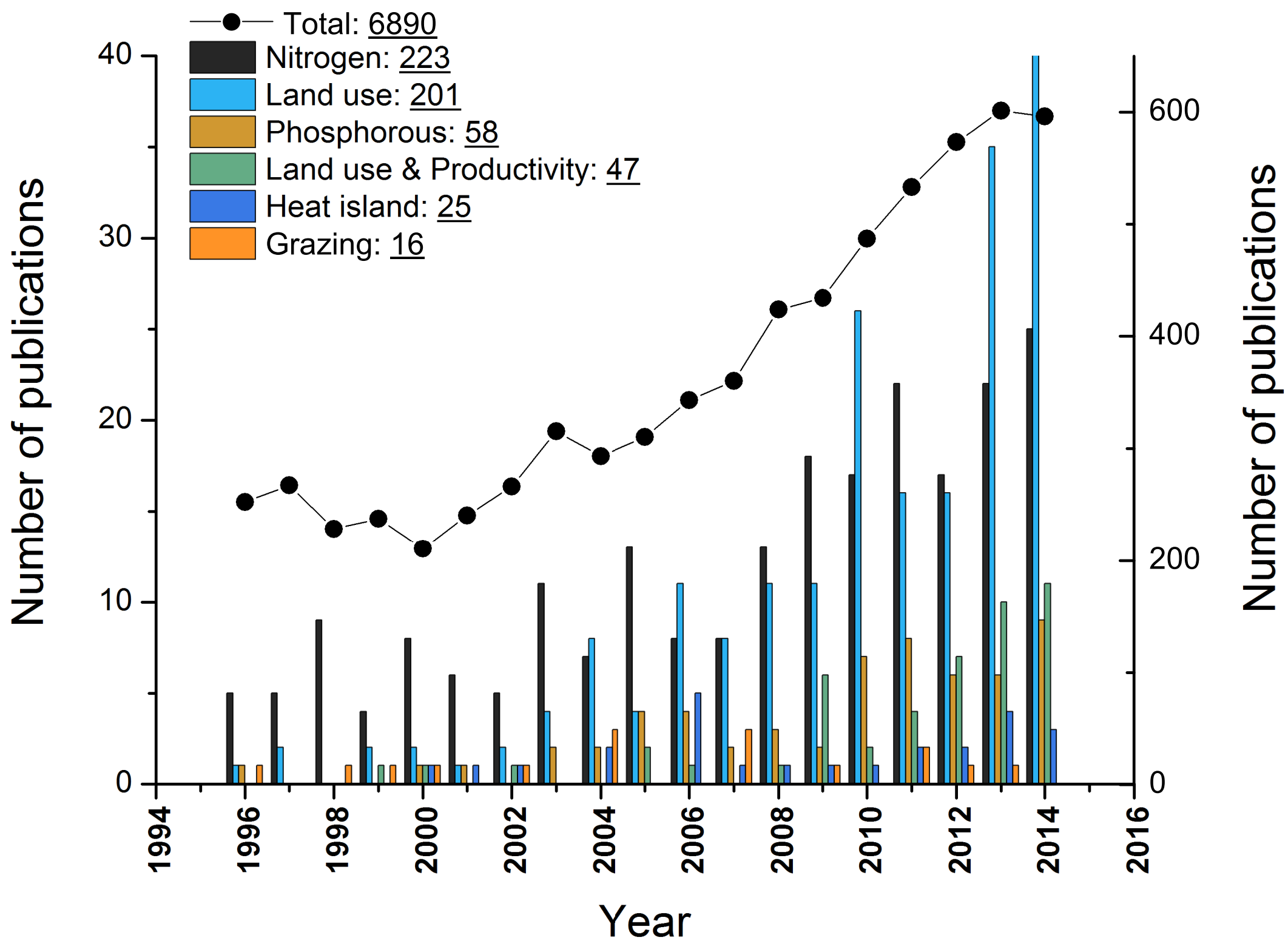



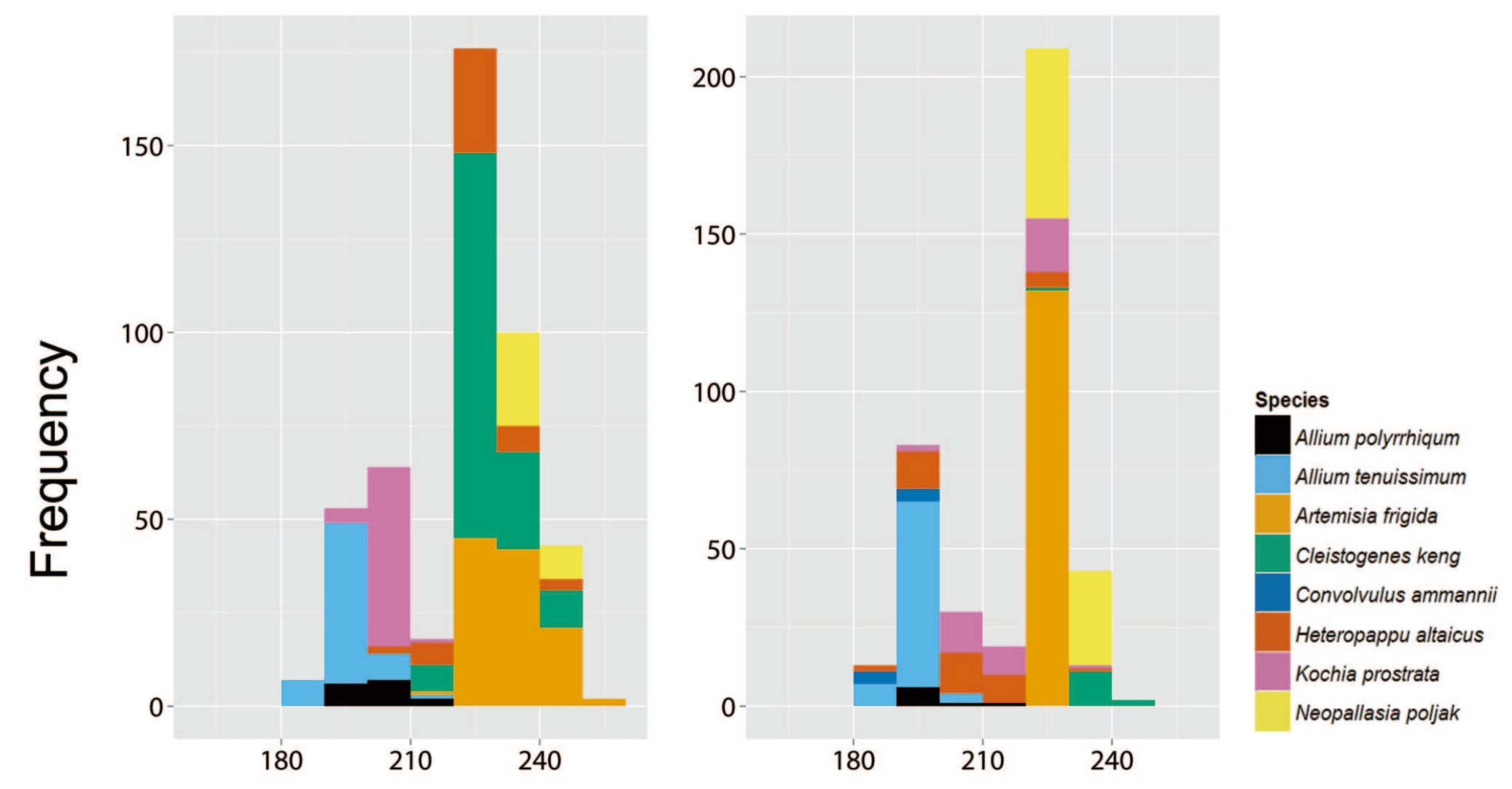

Flowering time 
Fig. 3

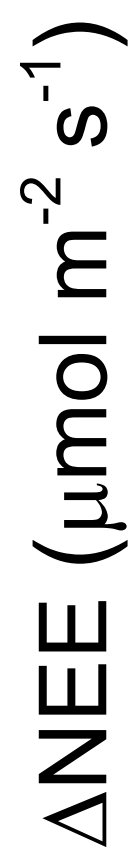

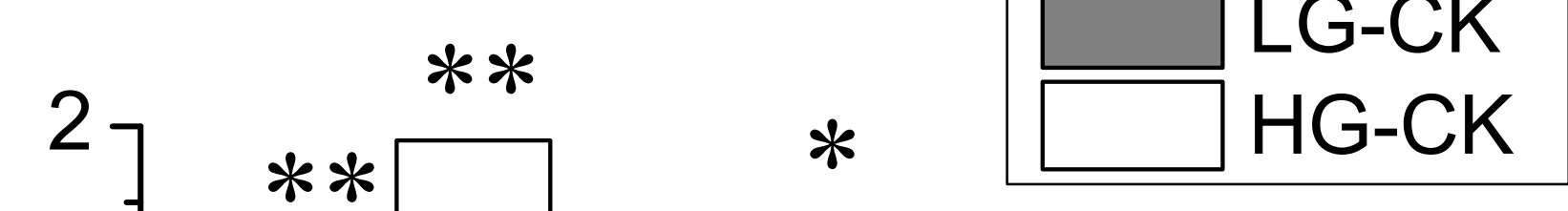

"o



'

$-2$

$-2.0$

0

**

(b)

-1.5
-1.0
-0.5
0.0

$*$

$-2$
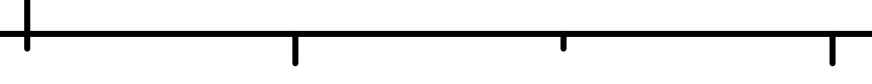

(2)

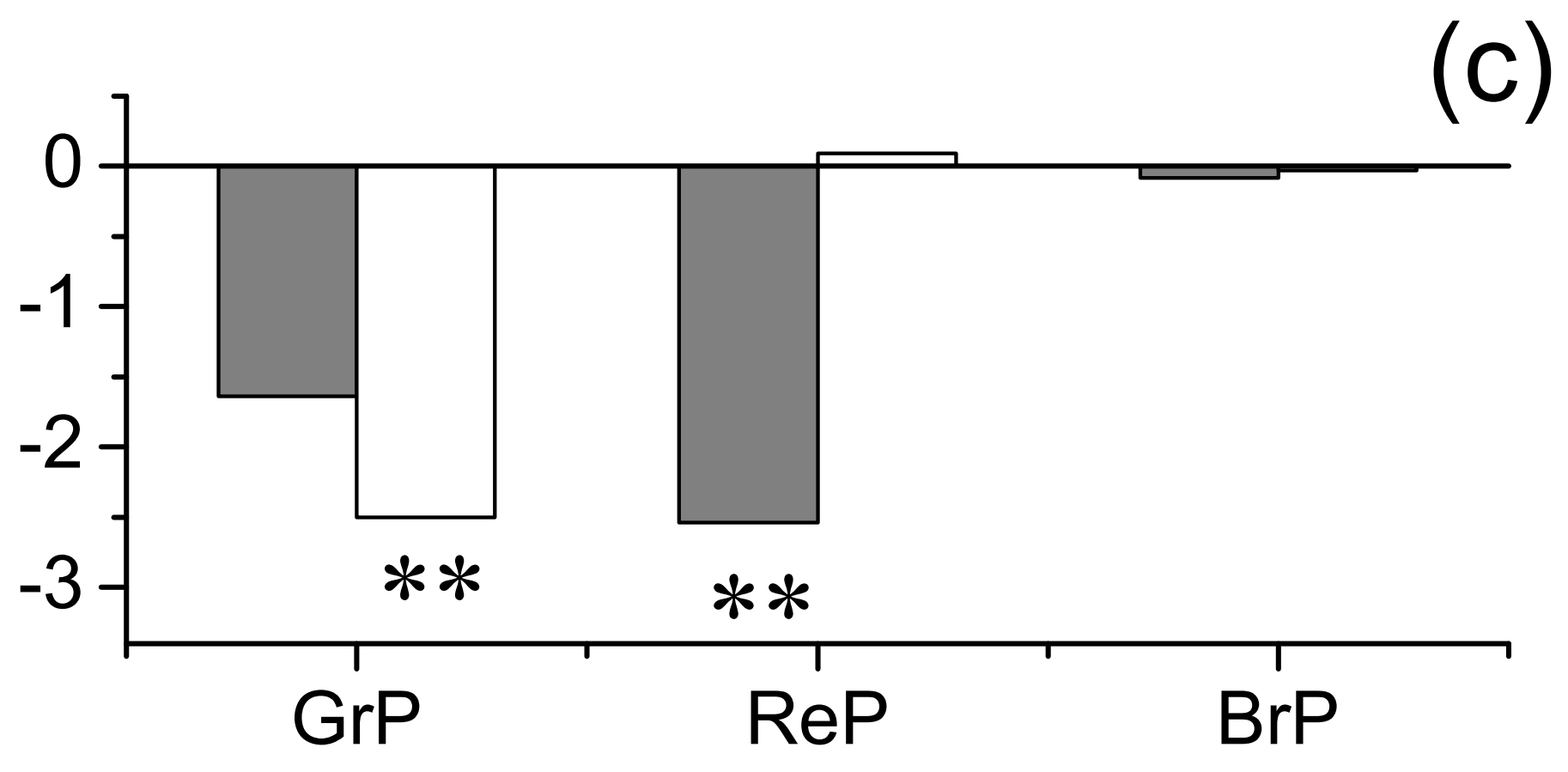

0

Phenophases 
Fig. 4

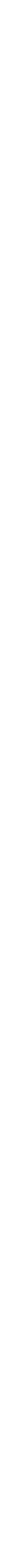


Fig. 6

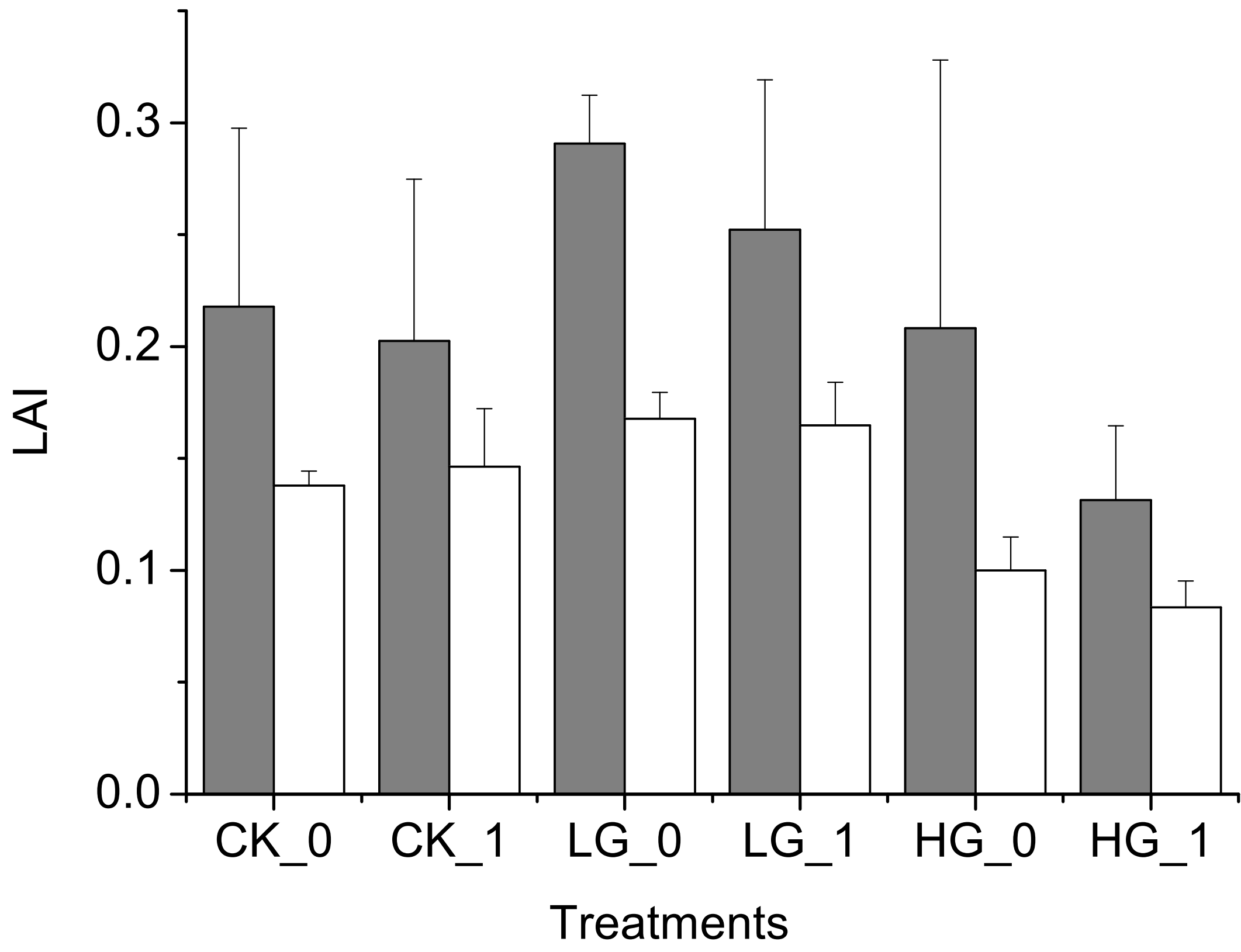

